\title{
LAS CARTAS DE BLASCO IBÁÑ̃̃ AL MARQUÉS DE DOSFUENTES
}

\author{
LUIS RUBIO GARCÍA \\ Universidad de Murcia
}

En el «Fondo Cultural Espín», ubicado en Lorca, que con tanto celo tutela la Caja de Ahorros del Mediterráneo se hallan depositados ciertos documentos que pertenecieron al Archivo del Marqués de Dosfuentes.

Don Fernando de Antón del Olmet, Marqués de Dosfuentes, nació en Huelva en 1872 y pronto sus estudios le llevarían a ingresar en la carrera diplomática, en la que ocupó diversos empleos en una serie de embajadas tanto de Europa, como de América y Asia, hasta su jubilación en 1930.

Amante de la literatura compuso varias obras, y sobre todo colaboró en periódicos y revistas, de modo especial en «La Ilustración Española y Americana». Miembro de Academias y Fundaciones frecuentó ambientes intelectuales y círculos literarios, y de ese modo se ganó el aprecio de relevantes personalidades. Aficionado a los autógrafos poseía un álbum de ellos, conservado en el citado «Fondo Cultural Espín», juntamente con algunas cartas de eruditos y escritores representativos de su tiempo, y entre ellas se encuentran éstas de Blasco Ibáñez, con quien se relacionó por su cargo diplomático en Pekín, ciudad que visitaría el novelista valenciano en uno de sus frecuentes viajes.

Del encuentro en Pekín surgiría una auténtica amistad y fruto de ello sería la correspondencia cruzada entre ambos. Las epístolas que aportamos son cinco, todas ellas de Blasco Ibáñez dirigidas al Marqués de Dosfuentes, e ignoramos por otra parte las respuestas. Se sitúan entre los años 1924 y 1926, ya en edad avanzada del escritor, que como es sabido, fallecería en su residencia de Menton, el 28 de enero de 1928.

La primera de ellas manuscrita la envía desde Hong-Kong a Pekín con fecha del 12 de enero de 1924.

Las otras proceden de Menton (Francia), donde fijó su residencia y están escritas a máquina con firma y rúbrica del autor, y que a continuación relacionamos:

1. Del 21 de abril de 1924.

2. Del 5 de agosto de 1925. 
3. ${ }^{a} \quad$ Del 30 de junio de 1926.

4. ${ }^{\mathrm{a}} \quad$ Del 6 de septiembre de $1926^{1}$.

La amistad y afecto de Blasco Ibáñez por el Marqués de Dosfuentes se debe a la calurosa recepción y buen trato que recibió, como hemos insinuado, a su paso por Pekín, por parte de la representación diplomática que por aquel entonces ostentaba D. Fernando de Antón del Olmet.

Otro motivo que nos explicaría asimismo la amistad entre ambos personajes, soslayando sus divergencias políticas, consistiría en que Blasco Ibáñez se encontraba por aquel entonces en el cénit de su fama de escritor, mientras el Marqués de Dosfuentes pugnaba por obtener un reconocimiento en sus escarceos literarios, y comprensiblemente buscaba el respaldo del ya famoso novelista valenciano.

En la primera de las cartas remitida a Pekín desde Hong-Kong en 12 de enero de 1924, elogia Blasco Ibáñez la obra del diplomático El alma nacional, al tiempo que a su regreso a Europa se ofrece para efectuar gestiones al objeto de publicarla en Francia.

En la segunda misiva del 21 de abril enviada a Pekín ya desde Menton, y desconociendo si el diplomático todavía se encontraba en la capital china o ya había salido para Europa le manda un raro volumen, adquirido en Madrid en un librero de viejos, de Vargas Machuca, titulado Milicia Indiana, y que como indica «fue como un Manual de los guerreros españoles en América». En el envío incluye Blasco Ibáñez los tres últimos volúmenes editados.

En la tercera carta expedida también desde Menton, en 5 de agosto de 1925, notifica al Marqués su boda con Elena en el Ayuntamiento de Menton, acontecimiento que deseaban guardar en secreto por lo menos hasta noviembre o diciembre, pero no fue posible, pues al enterarse los corresponsales de prensa, publicaron la fotografía de los recién casados saliendo de la alcaldía de Menton. Se alegra de que el Marqués se encuentre ya destinado a Europa, aunque, en su opinión, demasiado al Norte, si bien anuncia una proyectada visita a Noruega y Suecia. Igualmente le manifiesta que acababa de llegar con su mujer de un viaje en la Provenza, escenario de su próxima novela El Papa del Mar.

Reincide en otro párrafo Blasco Ibáñez con este tema de la novela, cuando señala de otras narraciones que se dispone redactar: «Chita se entretiene yendo a Montecarlo y yo voy a empezar a escribir El Papa del

1 Una detallada y emotiva descripción de la villa «Fontana Rosa», residencia del novelista en Menton, nos la ofrece su entrañable amigo y biógrafo Martínez de la Riva, y de allí provienen también la mayoría de las misivas que le dirigía el novelista.

Cf.: R. MARTíneZ DE LA RIVA, Blasco Ibáñez, su vida, su obra, su muerte, sus mejores páginas, Madrid, Editorial Mundo Latino, 1929. Vid. La Residencia de Blasco Ibáñez, pp. 145-152. Epistolario, pp. 155-181. 
Mar, que es la novela del Papa Luna. A continuación escribiré: A los pies de Venus (Los verdaderos Borgias), Las riquezas del Gran Kan (El verdadero Colón que usted conoce perfectamente)».

No olvida tampoco Blasco Ibáñez el libro de su amigo y le informa que una vez vertido al francés hará gestiones para su publicación en las conocidas editoriales Flammarion o Calmann-Levy.

La cuarta carta igualmente cursada desde Menton, pero ya del año siguiente, 30 de junio de 1926, la encabeza con un epígrafe: «Confidencial».

Aduce Blasco Ibáñez que en su paso por Madrid no se le ocurrió visitarle, en evitación de las consecuencias que pudieran derivarse, pues era de sobra conocida la ideología republicana del escritor y su rechazo a la monarquía: «La profesión del diplomático es muy vidriosa y más cuando se representa a un país atrasado y monárquico, como el nuesto, que es algo así como una pieza empolvada de museo de arte retrospectivo». Y más adelante se dolerá que la dedicatoria de un libro suyo haya podido causarle alguna contrariedad.

Decide veranear con su mujer en Suiza, con el proyecto de visitar el Norte de Europa. No encuentra traductor precisamente por ser verano y confía ocuparse en ello el próximo otoño.

Señala sobre su producción: "Yo he trabajado mucho en estos últimos meses, escribiendo mi novela sobre Colón, que se titula En busca del Gran Kan. Por este correo le remito mi última novela El Papa del Mar. Usted que tanto ama los estudios históricos tal vez la encontrará agradable».

La quinta carta proviene igualmente de Menton, y lleva la fecha del 26 de septiembre de 1926.

Se queja en ella Blasco Ibáñez, por las noticias llegadas a través del Marqués, de un artículo aparecido en la prensa de Madrid, y que según el escritor «solo contiene mentiras y disparates». Anuncia que no se propone ir a España, ni pensaba tampoco en el premio Nobel, que al parecer le iban a conceder «hace dos años», pero a raíz de un folleto político suyo, que armó mucho ruido, causaría la postergación, él mismo nos lo aclara: «La prueba del romanticismo con que hice esto la facilitan los hechos de que Maura y otros amigos estaban preparando la elección en la Academia Española y por unanimidad, y mis amigos y traductores de Noruega me preparaban lo del premio Nobel», pero el propio Blasco Ibáñez pediría a unos y a otros que renunciaran en sus gestiones, «y ellos fueron los primeros en conocer mi futura actitud». Y ya no había pensado más en el premio Nobel, más bien le preocupaban tres novelas que estaba preparando sobre el descubrimiento de América.

Se encontraba, pues, ocupadísimo trabajando hasta catorce horas diarias, como podría comprobar por los libros suyos que le enviaría. Y por la amistad con él, le escribía la carta personalmente, pues en otro caso, su secretario se encargaba de la correspondencia. 
Esta sería también la postrera carta, que poseemos, remitida por Blasco Ibáñez al Marqués de Dosfuentes. Hemos transcrito las epístolas, de la forma y manera con que se consignan, que muestran cierto desaliño familiar, especialmente con referencia a los acentos y signos de puntuación. Las reputamos de notorio alcance, no sólo para la biografía del escritor, sino también para la cronología y redacción de algunas de sus últimas creaciones.

Por su interés incluimos tres tarjetas autógrafas de Blasco Ibáñez para el Marqués de Dosfuentes, acompañando a cada tarjeta una novela del escritor.

Del Álbum del Marqués de Dosfuentes, recogemos igualmente un autógrafo de Blasco Ibáñez, así como su retrato con una dedicatoria.

HongKong, Enero 12, 1924.

Sr. D.

Fernando Anton del Olmet

Marques de Dosfuentes.

Pekin.

Querido Fernando: He terminado de leer «El alma nacional».

Es una obra simplemente magnifica y no hay que decir mas. Resulta un trabajo de alto patriotismo el procurar su difusion universal, haciendo que sea traducida à muchos idiomas y me place mucho contribuir á ello.

Empecemos por el francés. Cuando venga Vd. á Europa lo haremos inmediatamente. Pero convendría antes ocuparse de la traducción para ganar tiempo.

¿No hay ahi ningun frances algo literato que pudiera hacerla?

Sería para el una ocasion de que su nombre sonase en Paris, pues seguramente los periodicos (hablar)* de alla hablarán de la obra.

En fin: escribame sobre esto lo que juzgue oportuno.

Yo estaré a primeros de Abril en Menton ya sabe mis señas

$$
\begin{gathered}
\text { Villa Fontana Rosa } \\
\text { Menton } \\
\text { (Alpes Maritimes) }
\end{gathered}
$$

France.

Un ruego querido Fernando he sabido que la ultima noche que estuve en ese hotel, mientras Vd. y yo tomabamos cafe y los demas amigos pre-

\footnotetext{
* Tachado en el original.
} 
senciaban en el hall las suertes del prestidigitador chino, el encargado de negocios de Mejico y su esposa me buscaron inutilmente y se fueron.

Yo les habia invitado á esta visita y siento muchisimo aparecer como un hombre desatento aunque sea involuntariamente.

Se trata ademas de personas que me fueron muy simpaticas y con las cuales verdaderamente deseaba conversar.

Le ruego que les presente mis excusas por esta falta que fue obra de la casualidad. Lamento mucho que no se les ocurriera buscarnos en el comedor.

Digales que en Menton me tienen á sus ordenes deseando serles grato, y si no vienen por alla espero verlos cuando yo vuelva a Pekin.

Me esperan en Manila filipinos y españoles, cordialmente unidos para hacerme un recibimiento ruidoso. Voy á dar una conferencia en el teatro mas grande de allá. Lo que (lo que debe y ha sido España para)* ha hecho España para el progreso de la humanidad.

Termino esta carta.

Me estan esperando varios amigos de HongKong. Una vida demasiado atareada y vertiginosa la que llevo en este viaje.

Mis saludos a todos los amigos.

Un abrazo de su fraternal amigo y admirador.

Vicente Blasco Ibañez (rubricado)

\author{
Membrete: Vicente Blasco Ibañez \\ Villa Fontana Rosa \\ Menton (Alpes Maritimes)
}

\title{
21 Abril 1924
}

Sr. D. Fernando Anton del Olmet.

Pekin

Querido Fernando: Ya estoy aqui en esta su casa y tanto Chita como yo le repetimos nuestro agradecimiento por las atenciones que tuvo con nosotros a nuestro paso por Pekin.

He tardado unos dias en escribirle porque no quería hacerlo sin cumplir una promesa. Recordará usted que le hablé del célebre y raro libro del conquistador Vargas Machuca, titulado «Milicia Indiana», y que fue como un Manual de los guerreros españoles en América. Apenas llegué pedi este libro a los libreros de viejo de Madrid y por este mismo correo se le en-

\footnotetext{
* Línea tachada en el original.
} 
vio en paquete certificado. me ha costado mucho encontrarlo. Pensé enviarle encuadernados los dos pequeños volumenes pero esto hubiese retrasado mucho el envio, y prefiero remitirselos en rústica para que los tenga antes. Se que le van a gustar mucho. Usted que ha cantado como nadie el alma heroica española necesitaba tener estos dos pequeños tomos.

Creo que habra visto en el «A B C» las fotografias que sacó Chita y en las que figuramos la señorita Prat, usted y yo.

Le escribo con la duda de si esta carta llegará a sus manos inmediatamente o si estará usted camino de Europa como me anunció.

De un modo o de otro ya sabe que me tiene a sus ordenes, muy de veras, deseando ayudarle y servirle y que debe usted avisarme siempre su llegada.

Le ruego que salude en mi nombre a todos los amigos y amigas que conoci en su casa y cuyos nombres no menciono pues resultaría larguisimo.

Si por desgracia no viene usted a Europa este año ya sabe que aqui me tiene a su disposicion como si fuese «su Cónsul» y que todo lo que pueda hacer por usted lo haré con mucho gusto.

Chita me encarga mucho que le salude muy afectuosamente asi como a Elenita Prat de la que se acuerda con gran frecuencia.

Reciba un abrazo de su amigo, compañero y admirador.

\title{
Vicente Blasco Ibañez (rubricado)
}

P.D. En el mismo paquete que va la «Milicia Indiana» le envio los tres ultimos volumenes que he publicado.

\author{
Membrete: Vicente Blasco Ibañez \\ Villa Fontana Rosa \\ Menton (Alpes Maritimes) \\ 5 de agosto 1925.
}

Querido amigo y compañero: Le pido perdon por no haber contestado antes a su carta, pero emprendí un viaje a los pocos días de recibirla y luego han caido sobre mi numerosas y pesadisimas ocupaciones que absorben todo mi tiempo.

Voy a darle ante todo la noticia de que Elena y yo nos hemos casado aqui en Menton, el día 4 de Julio. Fué un acto que deseabamos guardar en secreto hasta Noviembre o Diciembre, pero se enteraron los corresponsales de los grandes diarios ingleses y americanos y nos fotografiaron cuando saliamos solos de la Alcaldía de Menton. La noticia y la fotografía han circulado por casi todos los diarios de la tierra. No se si la prensa de 
Noruega habrá hablado de esto. Los diarios españoles son los únicos que por imposición de la previa censura apenas si han podido dar la noticia en dos lineas.

No sabe cuanto celebramos que esté usted en Europa, aunque demasiado al Norte. Precisamente hace un año que estamos preparando un viaje a Suecia y Noruega. Pensábamos realizarlo este año, pero lo hemos dejado para el año próximo. Vamos especialmente a Stockholmo donde tengo un gran editor que publica mis libros traducidos al sueco, y numerosos amigos. De allí pasamos a Oslo, nombre feo en comparación con el antiguo de Kristianía.

Vamos después de esto a marcar bien las fechas para ver si de este modo podemos vernos antes.

Chita y yo acabamos de realizar un viaje por la Provenza donde he hecho estudios para la próxima novela «El Papa del Mar». Permaneceremos aquí todo el verano y a mediados de octubre iremos a París. Estaremos en París en Octubre, Noviembre y una parte de Diciembre. Si usted va a París en esa fecha dígamelo para combinar la manera de encontrarnos.

Celebro que se dedique a la traducción francesa de su libro y ya sabe que yo estoy dispuesto a servirle en todo lo que está al alcance de mi influencia, recomendando su publicación a la casa Flammarion o a la casa Calman-Levy; ya veremos cuando llegue el momento.

Me place mucho que le haya gustado lo que dije de usted en «La vuelta del mundo, de un novelista».

A mediados de este mes se publicará el tercer tomo de dicha obra y se lo enviaré para que la complete, pues creo que recibiría usted el primero y el segundo con dedicatoria que le envié a Pekín.

Nada mas por hoy. Como ya le he dicho nos quedamos todo el verano aquí. Chita se entretiene yendo a Montecarlo y yo voy a empezar a escribir «El Papa del Mar» que es la novela del Papa Luna. A continuación escribiré «A los pies de Venus» (Los verdaderos Borgia), «Las riquezas del Gran Kan» (El verdadero Colón que usted conoce perfectamente).

No le canso más. Afectuosos saludos de mi mujer y reciba usted un abrazo de su amigo y compañero que le recuerda continuamente

Vicente Blasco Ibañez (rubricado) 
30 Junio 1926.

\section{CONFIDENCIAL}

Querido Fernando: Ya sabe usted que los chulos de Madrid dicen que hay un sexto sentido "el de hacerse cargo», y yo no olvido nunca este sentido, procurando siempre darme exacta cuenta de las cosas. Por esto nunca se me ocurrió la posibilidad de ir a verle cuando pasase por esa capital.

La profesion de diplomatico es muy vidriosa y mas cuando se representa a un pais atrasado y monarquico, como el nuestro, que es algo asi como una pieza empolvada de museo de arte retrospectivo.

Este año vamos a veranear en Suiza. Se ha hecho ya tarde para ir al Norte de Europa. Creo que mi esposa y yo haremos dicho viaje el año que viene. $Y$ cuando pasemos por Oslo nos detendremos dos o tres dias nada mas, de puro incognito, pues a nosotros lo que nos interesa es ver los paisajes.

Siento que le haya acarreado contrariedades las palabras afectuosas de mi libro, referentes a usted, pero bien sabe que yo las escribi con la mejor intencion del mundo.

En lo que se refiere a su libro le diré que no puedo hacer nada con ningun traductor en ese momento, pues ya ha empezado el verano y todos ellos se han ido de París. Lo mismo ocurre con los editores. Trataré este asunto en Octubre o Noviembre, cuando yo vaya a París, pues pienso estar allá hasta principios de Enero.

Mi mujer y yo vamos ahora todos los años a París en estos primeros meses de invierno, volviéndonos aqui en los primeros dias de Enero, cuando empieza la temporada invernal.

Yo he trabajado mucho en estos ultimos meses, escribiendo mi novela sobre Colón, que se titula «En busca del Gran Kan».

Por este correo le remito mi ultima novela «El Papa del Mar». Usted que tanto ama los estudios historicos tal vez la encontrará agradable.

Nada más por hoy y reciba los cariñosos recuerdos de su amigo de siempre

Vicente Blasco Ibañez

(rubricado) 
Elena le saluda igualmente. No se si se enteraria usted que nos casamos hace un año, el 4 de Julio de 1925 . No dimos parte a nadie, pero publicaron la noticia con una fotografia nuestra los diarios ingleses, los de los Estados Unidos y muchisimos de otras naciones.

\section{Membrete: Vicente Blasco Ibañez \\ Villa Fontana Rosa \\ Menton (Alpes Maritimes)}

\section{Septiembre 1926.}

Querido amigo Fernando: Veo por lo que usted me indica en su carta, que el articulo publicado por la prensa de esa capital solo contiene mentiras y disparates. $\mathrm{Ni}$ yo me propongo ir ahi en otoño, ni pienso en lo del premio Nobel. Dicho premio me lo iban a dar hace dos años, cuando largué mi folleto politico que tanto ruido produjo. La prueba del romanticismo con que hice esto la facilitan los hechos de que Maura y otros amigos estaban preparando mi eleccion en la Academia Española por unanimidad, y mis amigos y traductores de Noruega me preparaban lo del premio Nobel. Yo por caballerosidad les escribi desde París, a unos y a otros, unos quince dias antes, anunciandoles lo que iba a hacer para que desistiesen de sus gestiones, y ellos fueron los primeros en conocer mi futura actitud. Después de esto ya no he vuelto a pensar en el premio Nobel. Otras cosas me traen preocupado, especialmente las tres novelas que estoy preparando sobre el descubrimiento de América.

Tampoco se me ha ocurrido jamás el dar conferencias en los paises escandinavos. No se quien ha podido inventar tal absurdo.

No le escribo mas por hoy. Estoy ocupadisimo, trabajando mas de catorce horas diarias. Dentro de unos meses, por los libros que recibirá usted mios, se irá dando cuenta de lo que he trabajado y lo que sigo trabajando. Únicamente escribo esta carta porque es para usted. Mi secretario se encarga de contestar toda la correspondencia.

Elena y yo le enviamos muy afectuosos recuerdos.

Vicente

(rubricado) 
(Tres tarjetas autógrafas, donde Blasco Ibáñez remite desde Menton tres obras suyas al Marqués de Dosfuentes)

A mi fraternal amigo, el eminente autor Fernando Antón del Olmet, Marqués de Dosfuentes, como recuerdo de gratitud por sus atenciones durante mi paso por Pekín.

\section{EL PRÉSTAMO DE LA DIFUNTA}

Vicente Blasco Ibañez

(rubricado)

Menton 1924.

Al eminente escritor Antón del Olmet, Marqués de Dosfuentes, su compañero, amigo y admirador.

\section{Vicente Blasco Ibañez (rubricado)}

\section{LA TIERRA DE TODOS}

Menton 1924.

A Fernando Antón del Olmet, gran autor del alma heroica española, su amigo y admirador.

\section{Vicente Blasco Ibañez (rubricado)}

\section{LA REINA CALAFIA}

Menton 1924.

(Se acompaña asimismo un impreso con las obras que han sido traducidas de Blasco Ibañez) 
(Entre los autógrafos recogidos por el Marqués de Dosfuentes, figura también el de Blasco Ibáñez)

Una vida sin ideal no vale la pena de ser vivida.

\section{Vicente Blasco Ibáñez (rubricado)}

\section{Pekín}

Enero 5, 1924.

(De esta misma fecha poseemos el retrato de Blasco Ibáñez, dedicado al Marqués de Dosfuentes, con la siguiente leyenda)

A mi amigo el eminente escritor Antón del Olmet, Marqués de Dosfuentes, como testimonio de afecto y admiración.

\section{Vicente Blasco Ibáñez}

(rubricado)

\section{Pekín}

Enero 1924. 
582

RLit, LXII, 124, 2000

LUIS RUBIO GARCÍA

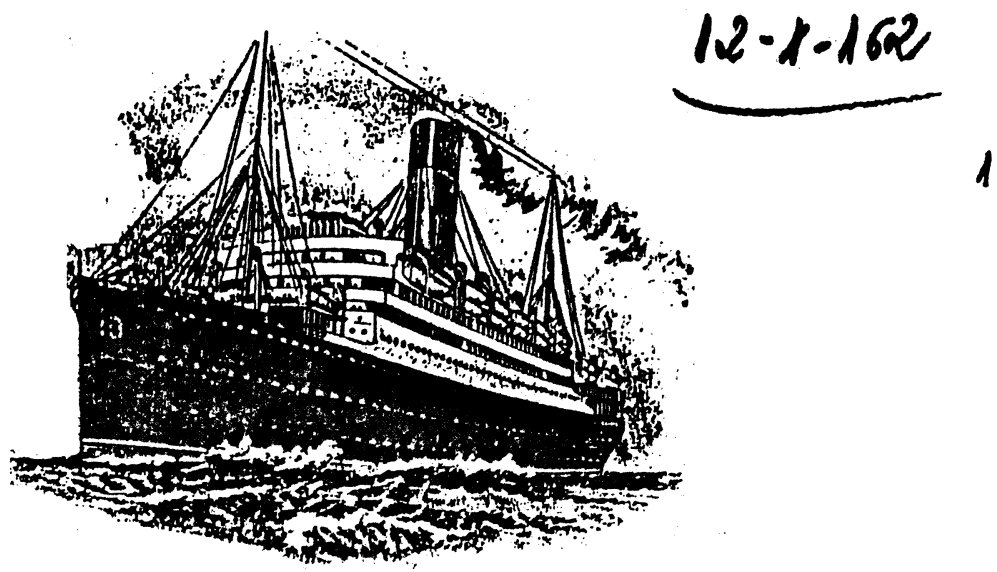

CunARD R.M.s."FRAN CONIA".

Fougt oug

$$
\text { Enevo } \frac{12}{1924}
$$

Sto. Di. Feviando Autou del Olunet Marver de Dosfuents
Petich

Snevids Feviando: the terminado ale leer "El alma nacivial".

Es une olva siuglemente naginfica o no hay vue decir mas. Presulta un tivabajo de alto

(c) Consejo Superior de Investigaciones Científicas

http://revistadeliteratura.revistas.csic.es

Licencia Creative Commons

Reconocimiento 4.0 Internacional (CC BY 4.0) 
LAS CARTAS DE BLASCO IBÁÑEZ AL MARQUÉS DE DOSFUENTES $\quad$ RLit, LXII, 124, 2000

583

vatuistionis el procurar molifirion miversal, haciends cue rear Tiadncida o' unchos idionas(t) a me jlace nancho contrilini a ello'..'

Eupecenos for el francé, b wando venga Val a' Enoga lo harenos innediata neinte. Pero convendia acites ocupoure de la traducción pava ganar tiengro.

¿No hay ahi niggin frances olgo litievato vie pudieva

(c) Consejo Superior de Investigaciones Científicas

http://revistadeliteratura.revistas.csic.es

icencia Creative Commons

Reconocimiento 4.0 Internacional (CC BY 4.0) 
584 RLit, LXII, 124, 2000

LUIS RUBIO GARCIA

hercerla?

2

Sevia vewai el mia ocasion de une su nowbre. vonare en Pari's. pres regrivamenté Los pevivalicos de alla Lablaván de la obra.

Eufin; ercribame oobre esto lo une $\alpha$ ing pre oport no. Wo estare a prinern de Alvil en heution Ya nabe un neñas Villa Foutana Rosa

Menton Fiance. (Alpes Mavitiun)

(c) Consejo Superior de Investigaciones Científicas

http://revistadeliteratura.revistas.csic.es

Reconocimiento 4.0 Internacior

Reconocimiento 4.0 Internacional (CC BY 4.0) 
LAS CARTAS DE BLASCO IBÁÑEZ AL MARQUÉS DE DOSFUENTES $\quad R L i t, L X I I, 124,2000$

585

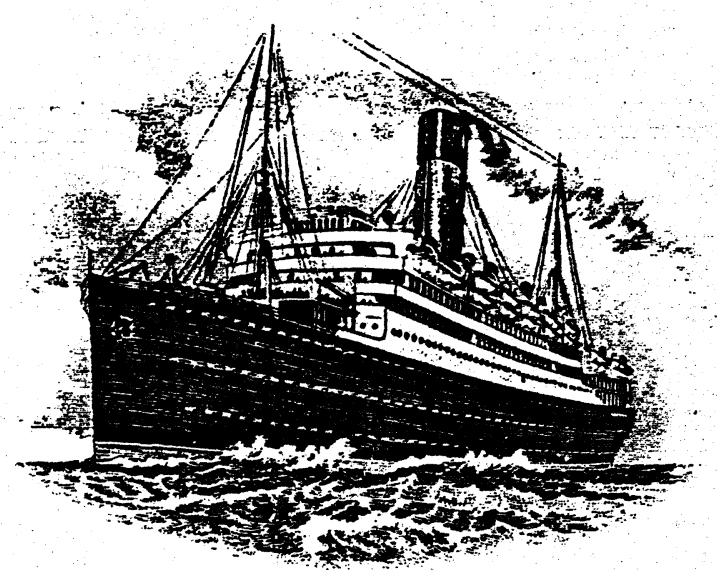

CUNARD R.M.S."FRANCONIA".

Eu ruego inevido Feruaudo tte salides une la ultima noche pue estuve en ese hotel, vientias $v_{a}$ d do tounabouns cafe a los denus amigos Viérencialan en el hall las mertes del prectidigita dor clivino, el encaugado de negocios abe Mejico

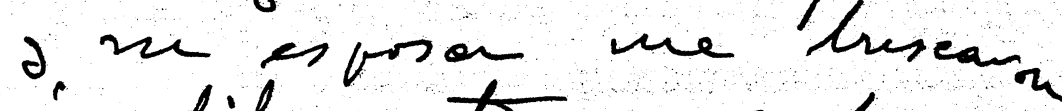
intiluments d re fuevon to les halien ivitad a csta visita d rieuto

(c) Consejo Superior de Investigaciones Científicas

http://revistadeliteratura.revistas.csic.es

Reconocimiento 4.0 Internacional (CC BY 4.0) 
$586 \quad$ RLit, LXII, 124, 2000

LUIS RUBIO GARCÍA

nuelinimo ofavecece 4 coun un howable desatento anupue rea involuntarímente

$$
\text { Se tuata }
$$

ole versours vie we fuero nuy nimpatices. o wor las cuales vevoladeramente dercalia convierrar.

íe vuego qune les presente wi escusas bor ecta falta cue fue olva de la casvalided. Fonvento mels ope no - les ocurvice uncarus en el conedor Digaler vne en Menton we tienein a' ws ordenes deseando verles grato, $\partial$ ri no. vienen for alla erpero varlos enando $d 0$ unelia a Petin.

(c) Consejo Superior de Investigaciones Científicas

http://revistadeliteratura.revistas.csic.es

Licencia Creative Commons

Reconocimiento 4.0 Internacional (CC BY 4.0) 
LAS CARTAS DE BLASCO IBÁÑEZ AL MARQUÉS DE DOSFUENTES RLit, LXII, 124, 2000

587

Me rveran en Manila filiviurs o evaciolen, cordial mente midos parra hacerme. un secilinimient vuidoso. Voy a der mia conferencia einel teatuo mas gramale de allá. Truma "To cue Evoma ha neelco Epaina vor el viogreno ole la lnmavidad". Termino iesta conta. Me estam esvevando varios anvigos de thengtorg. Wna vida diunariadoataveada a veutigiveosa lan pure llevo en ets viaj' mi saluolos a' todos Cos amigos. Wu alvaru de su fratend amigo o admivadr Vicents Blaseo Lente

(c) Consejo Superior de Investigaciones Científicas

http://revistadeliteratura.revistas.csic.es

Licencia Creative Commons

Reconocimiento 4.0 Internacional (CC BY 4.0) 
$588 \quad$ RLit, LXII, 124, 2000

LUIS RUBIO GARCÍA

A) mi freotermal amigo, el ensinents. aintor Firnando A ton del Olnet, werargen' de Dosfuents, corces vecuevels - De gratitud vor ins iteneines deweint uni vaso vor Petín EL PRÉSTAMO DE LA DIFUNTA

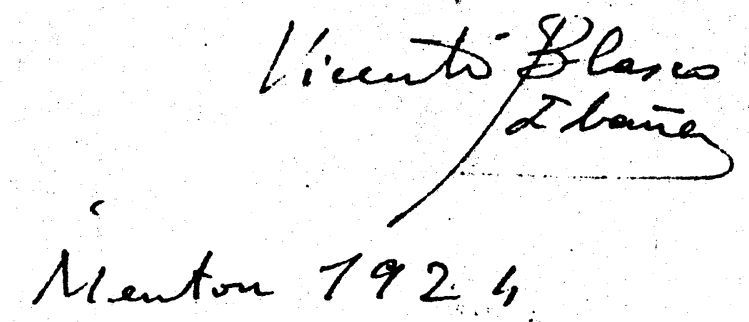

$12-1-168$

Al eimivent eicrito Auton' del Olunet, Mearme. de Dospuentes, in compentero a cenjo a nolmitador

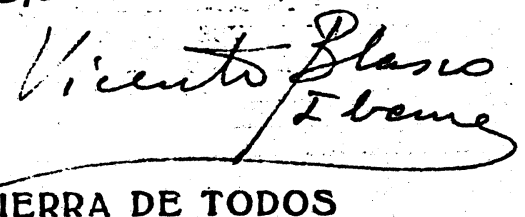

LA TIERRA DE TODOS

Mention 1924

(c) Consejo Superior de Investigaciones Científicas

http://revistadeliteratura.revistas.csic.es

Reconocimiento 4.0 Internacional (CC BY 4.0) 


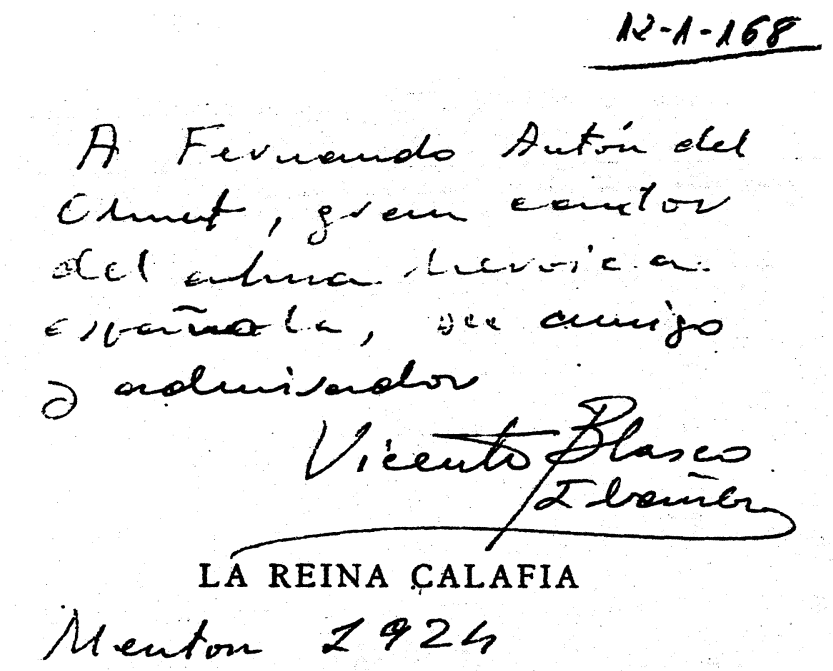

OBRAS TRADUCIDAS DEL AUTOR
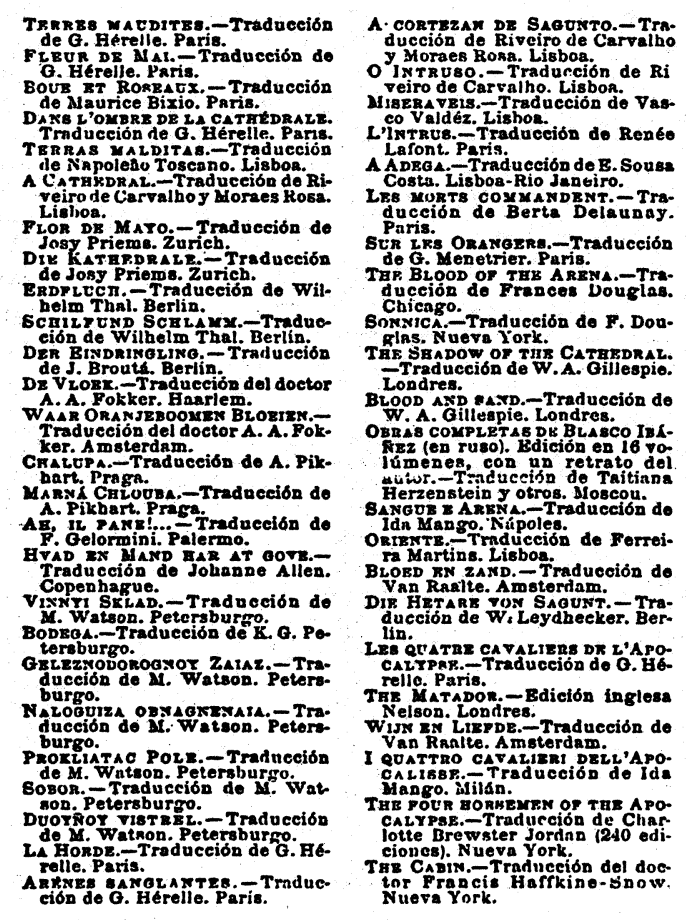


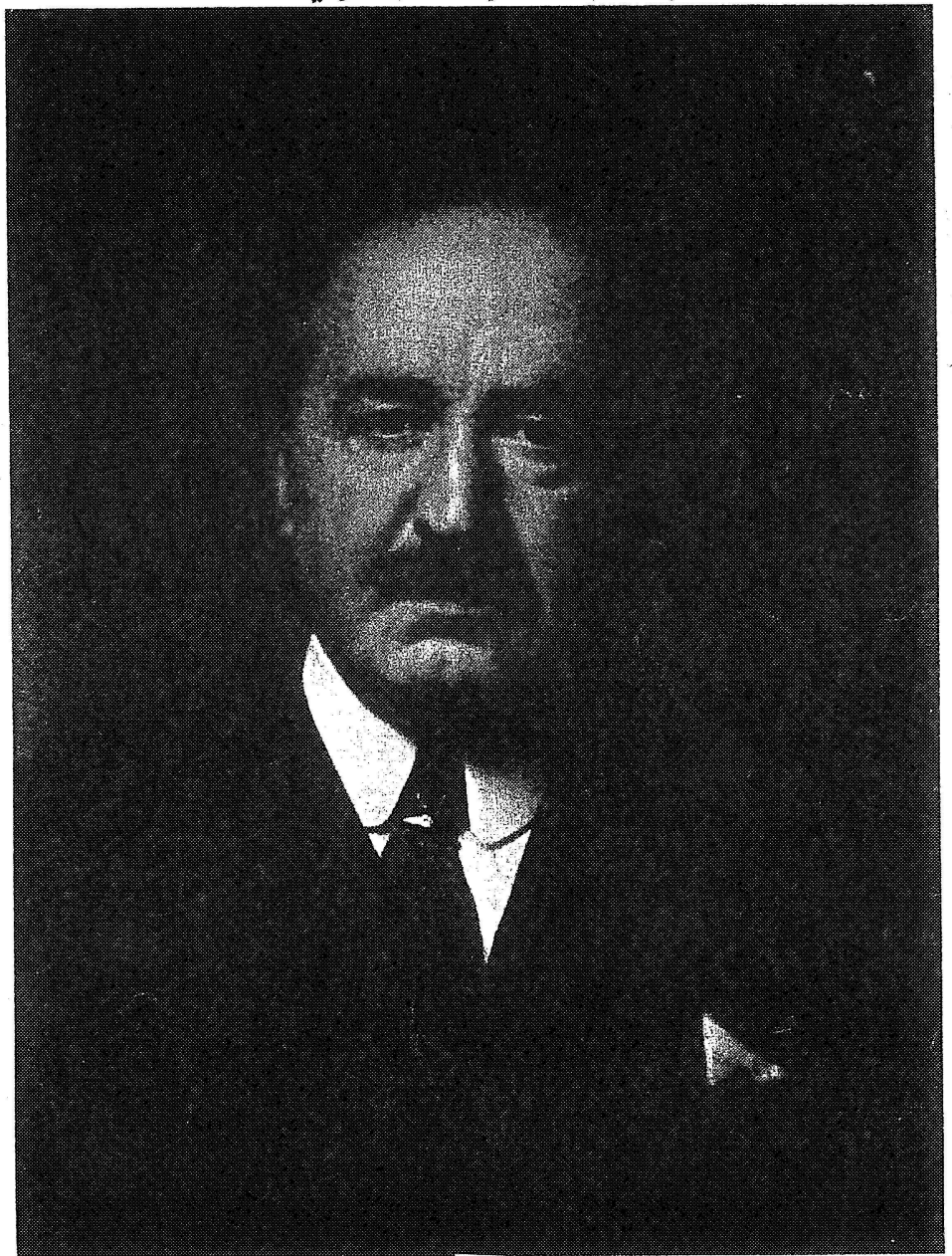

A ni anigo \&l eninents ercuito Aution del Olunat. Maverés de Dos Fuentes cono testimonio de affeto $\partial$ adurivacion PeKivino 1924 Vicentio Plareo 